\title{
Open Access: A remedy to the crisis in scientific inquiry?
}

Lars Wenaas, TIK-Center, University of Oslo, Oslo, Norway e-mail: larswen@tik.uio.no

The term 'crisis' seems to be used often when it comes to science; there is a crisis in the public trust in science, a replicability crisis, and the increase in retractions is denoted as a crisis. There is a validity crisis, a statistical crisis and there is a crisis in scholarly communication. The objective of this chapter is to comment on this framing and connect the notion of 'crisis' to normative factors which are central in other chapters in this book and ultimately discuss whether opening up science is a suitable remedy. Open Science is a toolbox designed to improve science, and in particular, Open Access is seen as the solution to the crisis in scholarly publishing. The principle of Open Access is that all scientific knowledge should be available for anyone to read and utilize. However, even if Open Access may be attractive for the researcher as a reader, the researcher as an author may hold a different position. A researcher in pursuit of a career needs to take into account prospects of future grants and tenure, and as a result, the choice of publishing outlet seems to be influenced by the incentives that follow journal ranks. The central idea of this chapter is that the choices made when publishing, are constrained by the quest for high-ranking journals, and this is likely the main source of many, if not all, of the crises in the science system. The quest for academic credits affects more than the final step of dissemination; it influences the research process and scientific conduct as a whole. The current arrangement of incentives is also in conflict with Open Science, particularly Open Access in respect to the scientific journal. This means other measures are needed to address the crisis, primarily new ways of research evaluation.

\section{Problem versus crisis}

It is not evident that all these alleged crises have earned their reputation as such. For instance, in 2011 it was reported that the number of articles retracted had increased tenfold during the previous 10 years, while the increase in articles expanded only by $44 \%$ (Van Noorden, 2011). However, an investigation reveals that only 4 papers out of 10,000 are retracted and the percentage of retracted papers has levelled out since 2012 (Brainard \& You, 2018). Fanelli argues that the increase in retractions on the contrary is a sign of integrity; the self-correcting mechanisms in the system works; retractions are a problem being dealt with (Fanelli, 2014). Another example is that the public trust in science is supposedly at a low point. However, according to NORC, an independent research organization at the University of Chicago, confidence in the scientific community in the USA has been stable for decades despite the divide in matters like climate change and food science (Funk \& Kennedy, 2017). Similar positive attitudes towards science can be found in the UK, where the public trust in scientists is at record high according to the Ipsos MORI Veracity Index (Stoye, 2017).

It might be debatable what constitutes a crisis and where to draw the line between a crisis and a serious problem, but clearly loannidis article 'Why most published research findings are false' (Ioannidis, 2005) is an example of the former if the state of science is in a condition as the title implies. Add this to the 'Sarewitz debate' on the supposedly abysmal state science is in, where 'Science isn't self-correcting, it's self-destructing' by science's detachment from real-world problem (Sarewitz, 2016), and there certainly seems to be room for improvements. In the social sciences, reproducibility in psychology has been under thorough investigation spearheaded by Brian Nosek. The Reproducibility Project is behind the study of the low reproducibility in psychological science where estimates hold that only $39 \%$ of studies are replicable (Open Science Collaboration, 2015). Journals of high reputation are not exempt from this effect as shown by a study on the replicability of 21 social science studies published in Science and Nature. Of the 21 studies, only 13 are replicable and equally important, with a significantly lower effect rate than in the original studies (Camerer et al., 2018). The scientific community is aware of these problems; $90 \%$ of 1576 researchers in a cross- 
disciplinary survey believes there is a (significant or slight) reproducibility crisis (Baker, 2016). Apparently the crises are recognized by scientists, however, what is the cause and what is the remedy?

\section{Normativity in science}

The replicability crisis ${ }^{1}$ is one of the focal points in Zickefeld and Schubert's chapter in this book, where they prescribe sound principles and thorough procedures for solid scientific practices very much aligned with the idea of Open Science (Zickefeld \& Schubert, 2019). Most notably, they emphasize the statistical competence and craftsmanship needed for proper scientific conduct. The replicability crisis is also central in Lundh's chapter, together with the validity crisis and the normativity crisis (Lundh, 2019). I believe like Lundh that the replicability crisis is connected and anchored in the normativity in science. Normativity in itself is not necessarily something negative; in his chapter, Brinkmann considers the presence of normativity of science self-evident as the quest for truth, validity, reliability and utility is a natural part of scientific practice (Brinkmann, 2019). In parts of his argument in the conclusion, he holds that value and normativity are integral parts of all human experience and that value judgments are important, not only to everyday life but also to the scholarly practices of psychology and social sciences. This is true, not just because of the inherently normative character of the human and social sciences where humans are the object of investigation. The value judgements and normativity extend to all disciplines and the whole science system as such, because humans are the ones conducting science. This makes the scientific endeavour as such a normative affair or at the very least an affair with normativity and value judgements as one of the main ingredients.

\section{Scholarly communication and normativity}

There are reasons to believe that our judgements surface in a negative way in how, where and why we publish: we adapt to the incentive system that governs science, we chase the prestige and renommée we ascribe to top-ranking journals and we publish to collect citations. These 'pellets of recognition' have become central in the quest for peer recognition (Merton, 1988) and are now the basic ingredient in research evaluation. At some point, it seems that strategic gaming behaviour has become an integrated part of our analytical methods that are selected to pursue publishing rather than the progress of science (Smaldino \& McElreath, 2016). Brian Nosek is more explicit and connects the reproducibility crisis and the crisis in scholarly communication directly. His claim is that the norms of publishing are a chase for novelty and positive results and a natural disregard for negative findings, which instigates research design and analysis primed for positive findings. This leads to an increase in false effects in the scholarly literature (Nosek, Spies, \& Motyl, 2012), an effect that seems to be more prevalent in the social sciences. Studies imply that the odds of reporting a positive result was 2.3 times higher in the social sciences than in the physical sciences, an effect ascribed to the relatively fewer constraints to both conscious and unconscious biases in the alleged 'softer' sciences (Fanelli, 2010).

If there is a causal trail between questionable research design and priming of results on the one hand and publishing in high-ranking journals on the other, then the normativity crisis as described by Lundh can be seen as the overarching structure which for a large part is governing most of, if not all, the other crises. The connection lies in a publication culture which through the incentive system fosters effects like hyperauthorship (loannidis, Klavans, \& Boyack, 2018), honorary and ghost

\footnotetext{
${ }^{1}$ Even if there are differences, replicability and reproducibility are commonly used interchangeably. For a discussion of this theme, see 'Replicability is not Reproducibility: Nor is it Good Science', 2009.
} 
authorship (Vera-Badillo et al., 2016), severe publication bias (Peplow, 2014) and an increase in inflated language and the use of positive wording (Vinkers, Tijdink, \& Otte, 2015). This appears to be systemic, the incentives simply make grounds for a natural selection of inferior science and requires 'no deliberate cheating nor loafing-by scientists, only that publication is a principal factor for career advancement' (Smaldino \& McElreath, 2016). Where a researcher publishes can be perceived as more important than the content itself (Macdonald \& Kam, 2007; Steele, Butler, \& Kingsley, 2006). This view is supported statistically; an optimality model for predicting the most rational research strategy favours small studies with a $10-40 \%$ statistical power, leading to false and erroneous conclusions in half of the published studies (Higginson \& Munafò, 2016).

If this line of reasoning is correct, the normativity crisis in essence is the source of the crisis in scholarly communication and the likely main cause of loannidis's claim; poor research design leads to false claims and low reproducibility. So, if we accept this diagnosis, if the scientific system is in a state of disease contaminated with a 'normative virus', what is the cure?

\section{Is Open Access the solution?}

It has been claimed that Open Science is the solution to the problems in research. Open Science proponents prescribe preregistration of studies, arrangements for publishing of negative or nonsignificant findings, open peer review, open access to both data and publications and openness in every aspect of science (Munafò et al., 2017). Many of these principles are recognized by financiers of science; National Institutes of Health (NIH), with their long-standing commitment for Open Access, has launched a plan for getting science back into 'self-correcting mode' in regard to reproducibility and addresses directly the normative problem of publishing in top- ranking journals (Collins \& Tabak, 2014). There is little doubt that Open Science in general prescribes sound procedures for proper scientific conduct, but it is not obvious that Open Science will remedy the normative intrusion in scholarly publishing. On the contrary, it is argued that Open Science practices as a general rule need to be complemented by the adoption of new research practices within the diciplines; adhering to 'open' is simply not enough (Chen et al., 2019).

Open Access is the part of Open Science that deals directly with scholarly publishing, and this will also be the scope of this chapter; in what way is Open Access the solution to the crisis in scholarly publishing and what are the obstacles for Open Access to become the preferred way of dissemination? The argument will start with investigating the problems Open Access is designed to solve, in what way Open Access conflicts with the incentive system governing science and ultimately why Open Access likely is not able to handle the full range of the scholarly publishing crisis.

In the centre of the crisis lie the academic journal and its role as an outlet for research and as the conveyor of academic credits. To understand why Open Access is incapable of being the sole solution, we must come to terms with the different flavours of Open Access and how publishing relates to the norms of science as expressed by Merton. We shall also need to investigate whether arguments against Open Access, primarily gold Open Access, are legitimate, especially viewed through the lens of the current arrangement of incentives.

\section{The different flavours of Open Access}

Open Access was first formalized through a series of declarations in 2002-2003 now known as the Budapest-Berlin-Bethesda initiative (Chan et al., 2002). The declarations are accompanied by three main implementations of Open Access: gold, green and hybrid. Gold Open Access is research articles published in journals using an appropriate license (Creative Commons or similar), letting the user read, download and text and data mine (TDM) the articles as long as proper attribution is done (Laakso et al., 2011). These permissions apply for the hybrid option as well, although a hybrid article 
still resides within a subscription-based journal, as opposed to a gold Open Access journal where all articles are free of use. An article is made green Open Access when a version of an article published in a subscription-based journal is deposited in an institutional or disciplinary repository and made publicly available after an embargo of normally 6-12 months (For some journals, the embargo period can be 3 years.) The version that may be deposited is generally not the publisher's version, but usually the (peer reviewed) version denoted as the post- print. Since the publisher's final version rarely can be deposited, the green alternative has traditionally been regarded less attractive by researchers. The arrangement of depositing is seldom accommodated with a proper license other than the publisher granting the rights for the deposit. Due to this, the legal status of TDM is often at best questionable, if not outright illegal. In the literature, one can further find contradictory concepts like 'Bronze Open Access' which is copyrighted material released free-to-read on the publishers website (Piwowar et al., 2018) and 'Black Open Access' being literature found on illegal piracy sites (Björk, 2017a; Green, 2017). Especially bronze Open Access is interesting, since the literatures' availability seems to address the goal of Open Access, but it should be pointed out that since no irrevocable reuse licence is issued, publishers can deny access to these articles at their discretion (Brock, 2018).

\section{Means to what kinds of problems?}

Open Access primarily addresses the lack of access to research literature for researchers working in institutions with scarce funding. Even at wealthy universities, library budgets are often too tight to accommodate the needs within the institutions. Open Access is further about opening up research to the general public and for exploitation in the private sector, following the principle argument of 'give to the taxpayers what the taxpayers have paid for'. The access problem is also closely related to the economic dysfunctionality in the academic publishing market. Access to scientific literature is achieved through increasingly expensive subscription schemes as the publishing business is dominated by a few large international publishers. Reed-Elsevier, Wiley-Blackwell, Springer and Taylor \& Francis are ranking at the top with profit margins ranging from 28\% to 38.9\% in 2012-2013 (Larivière, Haustein, \& Mongeon, 2015), resulting in over $€ 900$ million revenue for Elsevier (Times Higher Education, 2018). The financial structure and mechanisms have been well documented (Björk, 2017b; Larivière et al., 2015) and underline the journals' importance for the publisher as a very lucrative product. Journals are complementary products that cannot be substituted by one another, and since the publisher is the only supplier of a particular product, a market failure arises, and the prices act accordingly, creating an unsustainable economic situation for the subscribing institutions. The result is a state of oligopoly in the publishing industry (Larivière et al., 2015). So it is clear that Open Access is not only designed to solve suboptimal dissemination of knowledge (Tennant et al., 2016); it is motivated by economic savings and a dysfunctional academic publishing market. However, Open Access is first and foremost about the lack of access to scientific knowledge within the academic community and this is intimately connected to the ideals of science.

\section{The norms of science and the conflict with incentives}

The scholarly publishing system is generally seen as a dissemination cycle. The researchers conduct research, write articles and transfer them to the publisher who publishes journals, which in turn are being distributed through institutions back to the scientific community. Open Access aims at enhancing the step of distribution by making research publicly accessible for all and is consequently consistent with an important norm in science; openness. This central idea is found in the ideals of science as summarized in Merton's acronym CUDOS, where each letter designates the norms Communalism, Universalism, Disinterestedness, Originality and Scepticism. The norm of communalism describes the function where researchers give up their intellectual property rights in 
exchange for the social recognition of sharing the research and submitting it to the scrutiny of the scientific community (Merton, 1973). It has been argued that Open Access is a direct translation of Merton's communalism (Fecher \& Wagner, 2016). Willinsky has formulated this in the following way: 'open access is not just a child of the digital age, but the latest expression of longstanding principles of scholarly publishing having to do with the openness of science' (Willinsky, 2009, p. 53). Openness simply makes better science and better research output quite fitting the norms of science.

However, incentives are integrated into the dissemination cycle, and this interferes with another of the Mertonian norms, the one of disinterestedness. Merton formulated the norm of disinterestedness as conduct for the benefit of the scientific endeavour rather than for personal gain, motivated out of institutional control and sanctions including psychological conflict resulting from internalization of the norm (Merton, 1973). However, idealism in itself does not necessarily accommodate tenure; the researcher grants their research to the publishers in a trade-off for the academic credits, not only for dissemination purposes (Steele et al., 2006). This trade-off is primarily connected to the journal title, resulting in credits awarded according to the journals' prestige and rank in the pecking order. The journals' prestige is gained through previously published research and is therefore disconnected from the current research (Migheli \& Ramello, 2013). The researchers know how the incentive system works in the quest for grants and tenure; an international survey of 6344 researches representing all disciplines shows that dissemination of research is the primary motivation for publishing. However, almost equally important is the motivation for career advancement and the ability for future funding (Mulligan \& Mabe, 2006). In the Nature Publishing Group's author survey from 2015, factors driving the choice of where to submit articles ranked "the reputation of the journal" slightly over "the relevance to my discipline" in the STM-diciplines. In the humanities and social sciences, the order was the reverse, by a small margin. (Nature Publishing Group, 2015). The patterns in these surveys are not by coincidence, but arguably a predictable development following Merton's description of the trade-off for social recognition by sharing research. The journal does serve as vehicles of dissemination, but they are also vehicles of prestige, this is essential for researchers in their pursuit of a career. The norm of disinterestedness is consequently under pressure precisely because of the prominent role the incentives have gained in academic publishing. Interestingly enough, in a survey about contemporary support of Communism, Universalism and Disinterestedness among scientist, 'disinterestedness' came last of the three and was the single norm where academics agreed more with disconfirming statements than confirming ones (Macfarlane \& Cheng, 2008).

\section{Why Gold Open Access comes with limitations}

The highly debated 'Plan S' may serve as a lens to the importance of journals and the researcher respectively as a reader and a writer. Plan $S$ is a policy by a coalition of European research councils and funding agencies including the European Research Council, mandating Open Access publishing in all of their funded projects (cOAlition S, 2018). Demands for Open Access are not new in policies from research councils, institutions and governments; the novelty in Plan $S$ is the type of Open Access required to comply. Plan S accepts only gold Open Access journals; all other outlets are deemed not compliant ${ }^{2}$. This has a significant impact on the researcher's choice of outlets where estimates hold that $85 \%$ of all academic journal titles will not be eligible (Else, 2018). The debate on Plan $S$ is therefore useful as a backdrop to understand how the normative judgements in the publishing system unfold and why researchers protest against the intervention; they are deprived of

\footnotetext{
2 The criteria for which journals are eligible by the Plan S policy are still not finally settled by the time of writing. Following criticism against Plan $\mathrm{S}$, both hybrid and green open access may comply as a result of the hearing in 2019 , then under strict conditions.
} 
their favourite publishing outlets and the potential income of academic credits. This is considered a much bigger drawback than the advantages in getting access to the literature. Arguments against Plan S are that it could prove fatal for learned societies (Pells, 2018) and cause trouble for the next generation of researchers (Sveriges Unge Akademi, 2018), and it is unethical and cuts researchers off from the global community and leaves the quality at risk (Plan S Open Letter, n.d.; Schneider, 2018). The view on lower quality in Open Access journals is consistent with an international survey on the trustworthiness and authority of scholarly information where Open Access articles are less trusted by researchers, although the views on Open Access in the research system as such, interestingly, are positive (Tenopir et al., 2016).

Would the lack of eligible journals in Plan S be a problem if gold Open Access journals are of equally high quality as subscription-based journals? This topic has been addressed by Open Access proponents through numerous studies with claims of a citation advantage for Open Access. A list of studies was maintained up until 2015 by SPARC Europe, a Higher Education membership organization advocating Open Access, but is no longer maintained 'since the citation advantage evidence has now become far more common knowledge' (SPARC Europe, n.d.). The large body of literature on citation analysis (Rodrigues, Taga, \& dos Passos, 2016) indicates the importance of showing that Open Access publishing is at least equally rewarding as subscription-based publishing. However, since Open Access comes in three main flavours and two of them (green and hybrid) are based on the existing base of subscription- based journals, it is the gold Open Access citation advantage, which is important in respect to Plan S. When isolating and investigating gold Open Access journals, studies show a less clear picture. Through a journal impact factor analysis investigating all colours of Open Access, a study by Laakso and Björk concluded that Bronze Open Access articles (which in principle is not Open Access at all), on average have twice as high average citation rates compared to articles in closed subscription journals and three times as high as articles in gold journals (Laakso \& Björk, 2013). This is confirmed by the Piwowar study (Piwowar et al., 2018), leading to the conclusion that the 'clear citation advantage' can actually be read as a disadvantage for gold Open Access. The common narrative, as in the case of SPARC Europe, that Open Access as such gives a citation advantage may be correct, but not necessarily for gold Open Access journals specifically. So parts of the argumentation against Plan $\mathrm{S}$ do have legitimacy as the version of Open Access that complies with the policy (gold) is lagging behind in terms of citations compared to the versions of Open Access (green, hybrid) that do not comply. Plan S clearly shows that Open Access cause a tension within the current system of incentives and researchers perception of quality in science.

\section{Journals as a proxy for quality}

As Sovacool, Axen and Sorrel state in their article on appropriate research conduct, 'It is surely a "fool's errand" to try to define quality research in Academia' (Sovacool, Axsen, \& Sorrell, 2018, p. 1). Nevertheless, we do need some concept of quality for guidance, both in assessing good research and finding the right journal to publish. As Merton noted, citations are of high importance among researchers and generally regarded a sign of quality; the more the merrier. This make sense as citations are references to previous research, which acknowledges their role in the stock of knowledge. On an aggregated level, citations are an important component in the evaluation of research groups, departments, universities, research proposals, allocation of research funding and personnel. However, even if citations do indicate scientific impact and relevance, there is no evidence supporting that citations indicate anything substantial on other key characteristics of research quality like plausibility/ soundness, originality and societal impact (Aksnes, Langfeldt, \& Wouters, 2019). Citations also come with its own portfolio of problems, for instance excessive selfcitation (Seeber, Cattaneo, Meoli, \& Malighetti, 2019), citation rings (Sage, 2014) and researchers citing articles they never read (Simkin, 2003). These are effects that also can be traced back to the 
normativity in scientific publishing. Eugene Garfield noted 15 reasons to cite a paper (Garfield, 1996) including disclaiming or disputing the work of others; mere counting does not take these into consideration. The different motivations for citing disconnects citations from being a precise indicator of quality, however defined, and warns us on the overall use of citation metrics.

When citation counts are aggregated on the journal level and applied in research evaluation on the individual level, things get more troublesome. The journal impact factor (JIF ) is the most popular and well-known method in journal rankings but is a dubious measure for academic impact on the article level. JIF is a calculation invented by Garfield in 1972 and based on the number of citations in journal's articles according to a formula, spanning over the previous 2 years. It was originally intended for comparisons of journals within a specific discipline and was never intended for evaluation on the article level (Garfield, 1972). Since calculating a journals impact factor in a particular year is based on previous published results, there are obviously no substantial claims that can be made for articles published at a later stage. Furthermore, the distribution of citations within a journal shows that the most cited half of articles in a journal are cited ten times more often than the least cited half (Seglen, 1997). JIF is not statistically sound (Seglen, 1992), and there is no connection between an articles' quality and its outlet's JIF. This leads to a clear discouragement of using JIF as a proxy for quality on the article level altogether (Seglen, 1997). Studies argue that this discouragement does not only apply to JIF; all journal metric systems applied in research assessment are simply bad scientific practice (Brembs, Button, \& Munafò, 2013). This is further underlined by a study claiming that evaluating two articles by their respective journals' impact factor in most cases equals coin flipping (Brito \& Rodríguez-Navarro, 2019). In this respect, it is hardly helpful for Open Access proponents that Open Access journals approach the same academic impact in terms of JIF as subscription-based journals given comparable circumstances like age, discipline and country of publisher (Bjork \& Solomon, 2012). Even if Open Access journals are peers to subscription-based journals, Seglen's discouragement of evaluation by using JIF still stands. Whether the journal is open or not, journal metrics has serious limitations when used as sole means in research evaluation. It seems we are in need of something else. As stated by a frustrated researcher; 'we are told that the impact factor should no longer be used, but not told what to use instead' (Tregoning, 2018). Maybe this is not entirely correct.

\section{New ways of evaluating research}

The argument so far has been that normativity in academic publishing is the foundation for many of the problems in science and that there are limitations in the remedy of Open Science in general and in Open Access in particular. The challenges lies in both formal and informal systems of research evaluation, which are based on the journals' prominent role in the incentive system.

We should perhaps ask what the goal of implementing open practices really is. We could gain better access to the scientific literature by implementing Open Access (and thus conform better to the norm of communalism), and we could change the incentive system to make room for better scientific practice (and thus conform better to the norm of disinterestedness).

The relationship between the two goals can be illustrated by imagining flipping the existing portfolio of subscription-based journals to Open Access. It is hard to see how this would change the incentive system in any way; the journals would still be a part of journal ranks and used for evaluation. This may serve as an illustration of why Open Access in essence cannot deal with the normativity in scholarly publishing; by design it doesn't even try.

Further, addressing the one goal without the other could lead to conflicts since Open Access represents new requirements for researchers that disagree with the standards of the established academic fellowship. As in the case of Plan S, prestigious journals considered of high quality can be 
regarded non grata by policies. It may take years for journals to obtain high prestige, and many Open Access journals have yet to meet the top standards as perceived by the academic community (Migheli \& Ramello, 2013); these new requirements may simply be an obstacle for young researchers in pursuing a career. University departments and research fellowship are encouraging staff to publish in high-ranking and approved journals; a young researcher in the beginning of a career is expected to listen to the senior's advice and 'play the game'. Kam and Macdonald puts it like this: "what a quality journal is does not really matter, the agreement that there are such things matters very much indeed." This leads to 'gamesmanship'; the art of winning without cheating (Kam \& Macdonald, 2008). This is the game the aspiring researcher must learn in order to pursue a career.

Open Access will not change normative judgements in scholarly publishing, but normative judgements must change in order for scholarly publishing to become Open Access. Consequently, there is a need for ways of assessing research, which does not include journal ranks. The San Francisco Declaration on Research Assessment is such an initiative and states that research should be assessed on its own merits and journal metrics as JIF should be disregarded (DORA, 2012). The Leiden manifesto is also suggested as a starting point for responsible metrics (Hicks, Wouters, Waltman, de Rijcke, \& Rafols, 2015). Plan S is endorsing DORA, and its signatories intend to incorporate DORA and its requirements in their policies; this is an important contribution to a change in formal evaluation systems.

Neither DORA nor the Leiden manifesto explicitly connects to Open Science, but policies in the EU bridge Open Science, Open Access and research evaluation. EU sees open scientific practices as an important enhancer of innovation in the future. This view is elaborated in policy documents like 'Open Science, Open Innovation and Open to the World' and can be seen as a reinforcement of the social contract between science and society (European Commission, 2016). In this picture, Plan S is a natural policy-development, but for Open Science to happen, there is a need for a change in our evaluative measures. The European Commission has therefore issued a working report with the title 'Evaluation of Research Careers fully acknowledging Open Science Practices' emphasising a whole new range of evaluation mechanisms in the full spectre of Open Science:

For the practice of Open Science to become mainstream, it must be embedded in the evaluation of researchers at all stages of their career. This will require universities to change their approach in career assessment for recruitment and promotion. It will require funding agencies to reform the methods they use for awarding grants to researchers. It will require senior researchers to reform how they assess researchers when employing on funded research projects. (EU Commission, 2017)

The point that evaluation of research is the keystone in the promotion of Open Science is also the conclusion by an expert group in a EU-commissioned report on the future of scholarly publishing (EU Commission, 2019).

Institutions and governments clearly have an obligation to make sure systemic changes in evaluation are not a drawback for researchers. It is unfair to put obligations on researchers when conflicting rules of conduct directly influence the possibility of career advancement and scientific opportunities. This applies not only locally or nationally but also internationally. In the case of Plan S, European funders have a limited reach globally. Initiatives that call for a change in evaluation schemes must take the international dimension of science into account or risk a division between researchers depending on funding from Plan S signatories and those who do not. There is an additional warning. A global Open Access economy means a change in funding streams that could leave out academics in the global south or at other less funded institutions, due to the principle of pay-to-publish. A Max 
Planck white paper makes a strong case for there being enough money in the system globally to convert the entire subscription regime to Open Access, with potentially large savings after a transition (Schimmer \& Geshunhn, 2015). However, funds for subscriptions are not easily translated to funds for publishing; a change in streams must address that funds will be distributed disproportionally between institutions and countries and leaves researchers with scarce funding at risk financially. We run the risk of creating a new division, not between who can or cannot afford to read scientific articles, but one between those who can and cannot afford publishing.

\section{Conclusion}

The argument has been that there are serious problems in science, problems that can be traced back to the normative judgements in researcher's pursuit for grants, career and recognition. The pursuit is in itself both natural and commendable, but when incentives become the main target rather than solidity of scientific conduct, we need to adjust the course. There is an imbalance between the journal's function as an outlet for dissemination and its function for the allocation of academic credits. This imbalance is also obstructing the remedy that comes in form of Open Science practices. Open Science comes with limitations; in general it prescribes sound procedures for scientific conduct by opening up the research process and thus submitting it to the scrutiny of the scientific community. More transparency may mean better science, but even if all academic outlets switched from being subscription-based to Open Access, the incentives attached to the journals would still play a negative role if we continue to insist on judging the book by the cover. We run the risk of substituting the scholarly publishing system with a more open version where the Mertonian norm of disinterestedness is still severely challenged. The crucial point is therefore to change the evaluation schemes in science, the DORA declaration, the Leiden manifesto and assessment acknowledging Open Science practices being a good starting point. Incentives should discourage traditional closed practices and reward openness.

All incentive system has the power to change or reinforce behaviour. This is what incentives are designed for, and it should encourage stakeholders to be very careful in the way they are implemented. Researchers adapt to incentives, and we risk goal displacement: scoring high in assessment drills becomes the goal. A final point; we may fall into a trap formulated by Barry Schwartz:

When you rely on incentives, you undermine virtues. Then when you discover that you actually need people who want to do the right thing, those people don't exist because you've crushed anyone's desire to do the right thing with all these incentives. (Schwartz, 2009)

We started with the framing of crisis, but it's not particularly important nor interesting whether we use the term 'crisis' or 'problem'; what is important is that these issues are dealt with. In this respect, the studies and efforts by Nosek, loannidis and many others are clear signs of a self-correcting and self-governing mechanism in science.

If anything, these are initiatives that surely should be incentivized. 


\section{References}

Aksnes, D. W., Langfeldt, L., \& Wouters, P. (2019). Citations, citation indicators, and research quality: An overview of basic concepts and theories. SAGE Open, 9(1), 2158244019829575.

https://doi.org/10.1177/2158244019829575

Baker, M. (2016). 1,500 scientists lift the lid on reproducibility. Nature News, 533(7604), 452. https://doi.org/10.1038/533452a

Björk, B.-C. (2017a). Gold, green, and black open access. Learned Publishing, 30(2), 173-175. https://doi.org/10.1002/leap.1096

Björk, B.-C. (2017b). Scholarly journal publishing in transition- from restricted to open access. Electronic Markets, 27(2), 101-109. https://doi.org/10.1007/s12525-017-0249-2

Bjork, B. C., \& Solomon, D. (2012). Open access versus subscription journals: A comparison of scientific impact. BMC Medicine, 10, 73. https://doi.org/10.1186/1741-7015-10-73

Brainard, J., \& You, J. (2018, October 18). What a massive database of retracted papers reveals about science publishing's 'death penalty'. Retrieved October 28, 2018, from

https://www.sciencemag.org/news/2018/10/what-massive-database-retracted-papers-revealsabout-science- publishing-s-death-penalty

Brembs, B., Button, K., \& Munafò, M. (2013). Deep impact: Unintended consequences of journal rank. Frontiers in Human Neuroscience, 7, 291. https://doi.org/10.3389/fnhum.2013.00291

Brinkmann, S. (2019). Normativity in psychology and the social sciences: Questions of universality. In J. Valsiner (Ed.), Social philosophy of science for the social sciences. New York, NY: Springer.

Brito, R., \& Rodríguez-Navarro, A. (2019). Evaluating research and researchers by the journal impact factor: Is it better than coin flipping? Journal of Informetrics, 13(1), 314-324. https:// doi.org/10.1016/j.joi.2019.01.009

Brock, J. (2018). 'Bronze' open access supersedes green and gold. Retrieved from https://www. natureindex.com/news-blog/bronze-open-access-supersedes-green-and-gold

Camerer, C. F., Dreber, A., Holzmeister, F., Ho, T.-H., Huber, J., Johannesson, M., ... Wu, H. (2018). Evaluating the replicability of social science experiments in nature and science between 2010 and 2015. Nature Human Behaviour, 2(9), 637. https://doi.org/10.1038/s41562-018-0399-z

Chan, L., Cuplinskas, D., Eisen, M., Friend, F., Genova, Y., Guédon, J.-C., ... Kupryte, R. (2002). Budapest Open Access Initiative. Retrieved from http://www.budapestopenaccessinitiative.org/

Chen, X., Dallmeier-Tiessen, S., Dasler, R., Feger, S., Fokianos, P., Gonzalez, J. B., ... Neubert, S. (2019). Open is not enough. Nature Physics, 15(2), 113. https://doi.org/10.1038/ s41567-018-0342-2

cOAlition S. (2018). Plan S. Retrieved from https://khrono.no/files/2018/11/27/veileder\%20 Plan\%20S.pdf

Collins, F. S., \& Tabak, L. A. (2014). NIH plans to enhance reproducibility. Nature, 505(7485), 612-613.

DORA. (2012). DORA - San Francisco Declaration on Research Assessment (DORA). Retrieved May 11, 2018, from https://sfdora.org/

Else, H. (2018). Radical open-access plan could spell end to journal subscriptions. Nature, 561, 17. https://doi.org/10.1038/d41586-018-06178-7 
EU Commission. (2017). Evaluation of research careers fully acknowledging open science practices. Retrieved from https://doi.org/10.2777/75255

EU Commission. (2019). Future of scholarly publishing and scholarly communication: Report of the Expert Group to the European Commission. (Website). Retrieved from https://publications. europa.eu/en/publication-detail/-/publication/464477b3-2559-11e9-8d04-01aa75ed71a1

European Commission (Ed.). (2016). Open innovation, open science, open to the world: A vision for Europe. Luxembourg: Publications Office of the European Union.

Fanelli, D. (2010). "Positive" results increase down the hierarchy of the sciences. PLoS One, 5(4), e10068. https://doi.org/10.1371/journal.pone.0010068

Fanelli, D. (2014, April 30). Publishing: Rise in retractions is a signal of integrity. Nature, 509, 33. https://doi.org/10.1038/509033a

Fecher, B., \& Wagner, G. G. (2016). Open access, innovation, and research infrastructure. Publications, 4, 17. https://doi.org/10.3390/publications4020017

Funk, C., \& Kennedy, B. (2017). Public confidence in scientists has remained stable for decades. Retrieved November 16, 2018, from http://www.pewresearch.org/fact-tank/2017/04/06/ publicconfidence-in-scientists-has-remained-stable-for-decades/

Garfield, E. (1972). Citation analysis as a tool in journal evaluation. Science, 178(4060), 471-479.

Garfield, E. (1996). When to cite. The Library Quarterly: Information, Community, Policy, 66(4), 449458.

Green, T. (2017). We've failed: Pirate black open access is trumping green and gold and we must change our approach. Learned Publishing, 30(4), 325-329. https://doi.org/10.1002/leap.1116

Hicks, D., Wouters, P., Waltman, L., de Rijcke, S., \& Rafols, I. (2015). Bibliometrics: The Leiden manifesto for research metrics. Nature News, 520(7548), 429. https://doi.org/10.1038/520429a

Higginson, A. D., \& Munafò, M. R. (2016). Current incentives for scientists Lead to underpowered studies with erroneous conclusions. PLoS Biology, 14(11), e2000995. https://doi.org/10.1371/ journal.pbio.2000995

Ioannidis, J. P. A. (2005). Why Most published research findings are false. PLoS Medicine, 2(8), e124. Ioannidis, J. P. A., Klavans, R., \& Boyack, K. W. (2018). Thousands of scientists publish a paper every five days. Nature, 561(7722), 167. https://doi.org/10.1038/d41586-018-06185-8

Kam, J., \& Macdonald, S. (2008). Quality journals and gamesmanship in management studies. Management Research News, 31(8), 595-606. https://doi.org/10.1108/01409170810892154

Laakso, M., Welling, P., Bukvova, H., Nyman, L., Bjork, B. C., \& Hedlund, T. (2011). The development of open access journal publishing from 1993 to 2009. PLoS One, 6, e20961. https://doi.

org/10.1371/journal.pone.0020961

Laakso, M., \& Björk, B.-C. (2013). Delayed open access: An overlooked high-impact category of openly available scientific literature. Journal of the American Society for Information Science and Technology, 64(7), 1323-1329. https://doi.org/10.1002/asi.22856

Larivière, V., Haustein, S., \& Mongeon, P. (2015). The oligopoly of academic publishers in the digital era. PLoS One, 10(6), e0127502. https://doi.org/10.1371/journal.pone.0127502 
Lariviere, V., \& Sugimoto, C. R. (2018). The journal impact factor: A brief history, critique, and discussion of adverse effects. ArXiv:1801.08992 [Physics]. Retrieved from http://arxiv.org/ abs/1801.08992

Lundh, L. G. (2019). The crisis in psychological science, and the need for a person-oriented approach. In J. Valsiner (Ed.), Social philosophy of science for the social sciences. New York, NY: Springer.

Macdonald, S., \& Kam, J. (2007). Ring a ring o' roses: Quality journals and gamesmanship in management studies*. Journal of Management Studies, 44(4), 640-655. https://doi.

org/10.1111/j.1467-6486.2007.00704.x

Macfarlane, B., \& Cheng, M. (2008). Communism, universalism and disinterestedness: Re-examining contemporary support among academics for Merton's scientific norms. Journal of Academic Ethics, 6(1), 67-78. https://doi.org/10.1007/s10805-008-9055-y

Merton, R. K. (1973). The sociology of science: Theoretical and empirical investigations. Chicago, IL: University of Chicago Press.

Merton, R. K. (1988). The Matthew effect in science, II: Cumulative advantage and the symbolism of intellectual property. Isis, 79(4), 606-623. https://doi.org/10.1086/354848

Migheli, M., \& Ramello, G. B. (2013). Open access, social norms and publication choice. European Journal of Law and Economics, 35, 149-167. https://doi.org/10.1007/s10657-013-9388-x

Mulligan, A., \& Mabe, M. (2006). Journal futures: Researcher behaviour at early internet maturity. Presentation held at UKSG. Downloaded from https://www.uksg.org/sites/uksg.org/files/ imported/presentations8/mulligan.pdf

Munafò, M. R., Nosek, B. A., Bishop, D. V. M., Button, K. S., Chambers, C. D., Percie du Sert, N., ... Ioannidis, J. P. A. (2017). A manifesto for reproducible science. Nature Human Behaviour, 1(1), 0021. https://doi.org/10.1038/s41562-016-0021

Nature Publishing Group. (2015). Author Insights 2015 survey. Retrieved from https://figshare. com/articles/Author_Insights_2015_survey/1425362

Open Science Collaboration. (2015). Estimating the reproducibility of psychological science. Science, 349(6251), aac4716. https://doi.org/10.1126/science.aac4716

Nosek, B. A., Spies, J. R., \& Motyl, M. (2012). Scientific Utopia: II. Restructuring incentives and practices to promote truth over Publishability. Perspectives on Psychological Science, 7(6), 615-631. https://doi.org/10.1177/1745691612459058

Pells. (2018, October 19). Plan S 'could prove fatal' for learned societies. Times Higher Education (THE). Retrieved from https://www.timeshighereducation.com/news/ plan-s-could-prove-fatallearned-societies

Peplow, M. (2014). Social sciences suffer from severe publication bias. Nature News. https://doi. org/10.1038/nature.2014.15787

Piwowar, H., Priem, J., Larivière, V., Alperin, J. P., Matthias, L., Norlander, B., ... Haustein, S. (2018). The state of OA: A large-scale analysis of the prevalence and impact of open access articles. PeerJ, 6 , e4375. https://doi.org/10.7717/peerj.4375 
Plan S Open Letter. (n.d.). Retrieved January 5, 2019, from https://sites.google.com/view/ plansopenletter/home

Rodrigues, R. S., Taga, V., \& dos Passos, M. F. (2016). Research articles about open access indexed by Scopus: A content analysis. Publications, 4, 31. https://doi.org/10.3390/publications4040031 Sage. (2014). Retraction notice. Journal of Vibration and Control, 20(10), 1601-1604. https://doi. org/10.1177/1077546314541924

Sarewitz, D. (2016). Saving science. The New Atlantis. Number 49, Spring/Summer 2016, pp. 4-40. Schimmer, R., \& Geshunhn, K. (2015). Disrupting the subscription journals' business model for the necessary large-scale transformation to open access: A Max Planck Digital Library Open Access Policy White Paper. Retrieved from https://www.scienceopen.com/ document?id=b2341b73-1e0e-4b6f8ef0-15620638e1ba

Schneider, L. (2018, September 11). Response to Plan S from Academic Researchers: Unethical, Too Risky! Retrieved November 16, 2018, from https://forbetterscience.com/2018/09/11/ response-toplan-s-from-academic-researchers-unethical-too-risky/

Schwartz, B. (2009). Incentives are not enough. Retrieved October 20, 2018, from http://www. awakin.org/read/view.php?tid=608

Seeber, M., Cattaneo, M., Meoli, M., \& Malighetti, P. (2019). Self-citations as strategic response to the use of metrics for career decisions. Research Policy, 48(2), 478-491. https://doi. org/10.1016/j.respol.2017.12.004

Seglen, P. O. (1992). The skewness of science. Journal of the American Society for Information Science, 43(9), 628-638. https://doi.org/10.1002/

Seglen, P. O. (1997). Why the impact factor of journals should not be used for evaluating research. BMJ, 314(7079), 497. https://doi.org/10.1136/bmj.314.7079.497

Simkin, M. V. (2003). Read before You cite! Complex Systems, 14, 269-274.

Smaldino, P. E., \& McElreath, R. (2016). The natural selection of bad science. Open Science, 3(9), 160384. https://doi.org/10.1098/rsos.160384

Sovacool, B. K., Axsen, J., \& Sorrell, S. (2018). Promoting novelty, rigor, and style in energy social science: Towards codes of practice for appropriate methods and research design. Energy Research \& Social Science, 45, 12-42. https://doi.org/10.1016/j.erss.2018.07.007

SPARC Europe. (n.d.). The Open Access Citation Advantage Service (OACA). Retrieved May 12, 2018, from https://sparceurope.org/what-we-do/open-access/ sparc-europe-open-access-resources/openaccess-citation-advantage-service-oaca/

Steele, C., Butler, L., \& Kingsley, D. (2006). The publishing imperative: The pervasive influence of publication metrics. Learned Publishing, 19(4), 277-290. https://doi.

org/10.1087/095315106778690751

Stoye, E. (2017). Public trust in scientists at record high. Chemistry World. Retrieved from https:// www.chemistryworld.com/news/public-trust-in-scientists-at-record-high/3008394.article

Sveriges Unge Akademi. (2018). Plan S - open letter to decision makers - Sveriges Unga Akademi 
[text]. Retrieved November 15, 2018, from https://www.sverigesungaakademi.se/1447.html Tennant, J. P., Waldner, F., Jacques, D. C., Masuzzo, P., Collister, L. B., \& Hartgerink, C. H. (2016). The academic, economic and societal impacts of open access: An evidence-based review. F1000Res, 5, 632. https://doi.org/10.12688/f1000research.8460.3

Tenopir, C., Levine, K., Allard, S., Christian, L., Volentine, R., Boehm, R., ... Watkinson, A. (2016). Trustworthiness and authority of scholarly information in a digital age: Results of an international questionnaire. Journal of the Association for Information Science and Technology, 67(10), 23442361. https://doi.org/10.1002/asi.23598

Times Higher Education. (2018, February 20). Elsevier's profits swell to more than $f 900$ million. Times Higher Education (THE). Retrieved from https://www.timeshighereducation.com/news/ elseviersprofits-swell-more-ps900-million

Tregoning, J. (2018, June 19). How will you judge me if not by impact factor? Nature, 558(7710), 345. https://doi.org/10.1038/d41586-018-05467-5

Van Noorden, R. (2011). Science publishing: The trouble with retractions. Nature News, 478(7367), 26-28. https://doi.org/10.1038/478026a

Vera-Badillo, F. E., Napoleone, M., Krzyzanowska, M. K., Alibhai, S. M. H., Chan, A.-W., Ocana, A., ... Tannock, I. F. (2016). Honorary and ghost authorship in reports of randomised clinical trials in oncology. European Journal of Cancer, 66, 1-8. https://doi.org/10.1016/j. ejca.2016.06.023

Vinkers, C. H., Tijdink, J. K., \& Otte, W. M. (2015). Use of positive and negative words in scientific PubMed abstracts between 1974 and 2014: Retrospective analysis. BMJ, 351, h6467.

https://doi.org/10.1136/bmj.h6467

Willinsky, J. (2009). The stratified economics of open access. Economic Analysis and Policy, 39(1), $53-$ 70. https://doi.org/10.1016/\$0313-5926(09)50043-4

Zhang, L., Rousseau, R., \& Sivertsen, G. (2017). Science deserves to be judged by its contents, not by its wrapping: Revisiting Seglen's work on journal impact and research evaluation. PLoS One, 12(3), e0174205. https://doi.org/10.1371/journal.pone.0174205

Zickefeld, J., \& Schubert, T. (2019). How to identify and how to conduct research that is informative and reproducible. In J. Valsiner (Ed.), Social philosophy of science for the social sciences. New York, NY: Springer. 